\title{
CÉLULAS MADRE: LIMITACIONES Y OPORTUNIDADES EN EL PERÚ
}

\author{
José Amiel-Pérez ${ }^{1, a}$, Fanny Casado 2,b
}

\begin{abstract}
RESUMEN
Las células madre o células troncales (stem cells, en inglés) se definen como células poco frecuentes que poseen las características de dividirse asimétricamente mediante un proceso conocido como autorrenovación, y su potencial para distinguirse en más de un tipo de célula terminalmente diferenciada. Existen diversos tipos de células madre los cuales incluyen: las células madre embrionarias, que existen solo en las primeras etapas del desarrollo y varios tipos de células madre adulta que, a su vez, incluyen tejidos específicos o derivados de tejidos estromales o mesenquimales. Asimismo, se pueden generar por ingeniería genética, células con propiedades similares a las células madre embrionarias, pero derivadas de tejidos adultos y sin limitaciones éticas y legales que se denominan células madre pluripotentes inducidas. En todos estos casos, existen muchas incógnitas que se siguen trabajando en la ciencia básica para informar mejor a la práctica clínica. En el Perú se están afinando técnicas y mejorando metodologías que aún requieren perfeccionamiento, mejor equipamiento y mayor especialización de los recursos humanos, pero constituyen un loable esfuerzo en favor de una destacada posición internacional y el desarrollo futuro en el área de células madre.
\end{abstract}

Palabras clave: Células madre; Medicina regenerativa; Ingeniería de tejidos (fuente: DeCS BIREME).

\section{STEM CELLS: LIMITATIONS AND OPPORTUNITIES IN PERU}

\begin{abstract}
Stem cells are defined as rare cells that are characterized by asymmetric division, a process known as self-renewal, and the potential to differentiate into more than one type of terminally differentiated cell. There is a diversity of stem cells including embryonic stem cells, which exist only during the first stages of human development, and many adult stem cells depending on the specific tissues from where they derive or the ones derived from mesenchymal or stromal tissues. On the other hand, there are induced pluripotent stem cells generated by genetic engineering with similar properties to embryonic stem cells that are derived from adult tissues without the ethical and legal limitations. In all cases, there are many questions that are being addressed by research in basic sciences to better inform clinical practice. In Peru, there is much to do refining techniques and improving methodologies, which requires experience, proper facilities and highly specialized human resources. However, there are interesting efforts to place Peruvian stem cell research in the international scientific arena.
\end{abstract}

Key words: Stem cells; Regenerative medicine; Tissue engineering (source MeSH).

\section{INTRODUCCIÓN}

Las células madre (CM) o células troncales (stem cells, en inglés) se definen como células poco frecuentes que poseen las características de dividirse asimétricamente mediante un proceso conocido como autorrenovación y su potencial para distinguirse en más de un tipo de célula terminalmente diferenciada. La división asimétrica celular es un proceso en el que una de las células será también una célula madre y la otra una célula diferenciada, de acuerdo con las condiciones ambientales en las que ocurre el proceso.
Las CM son fundamentales, porque de ellas dependen los múltiples tipos de células que conforman las plantas, animales y humanos, a lo largo de las diversas etapas del ciclo vital. Las CM son células indiferenciadas que, potencialmente, pueden transformarse en células especializadas - diferenciadas - y naturalmente cumplir el rol de células reparadoras del cuerpo. Pueden utilizarse en medicina regenerativa para reemplazar células muertas y tejidos afectados por enfermedades o accidentes. Al reemplazar células y tejidos se espera restaurar las funciones que tenían las células originales y logren la cura definitiva, total, de los pacientes, y no

\footnotetext{
Laboratorio de Cultivos Celulares, Universidad Científica del Sur. Lima, Perú.

Stem Cell and Cancer Research Institute, McMaster University. Hamilton, Canadá.

Químico farmacéutico, doctor en Farmacia y Bioquímica; ' química, doctora en Toxicología

Recibido: 17-09-15 Aprobado: 18-11-15
} 


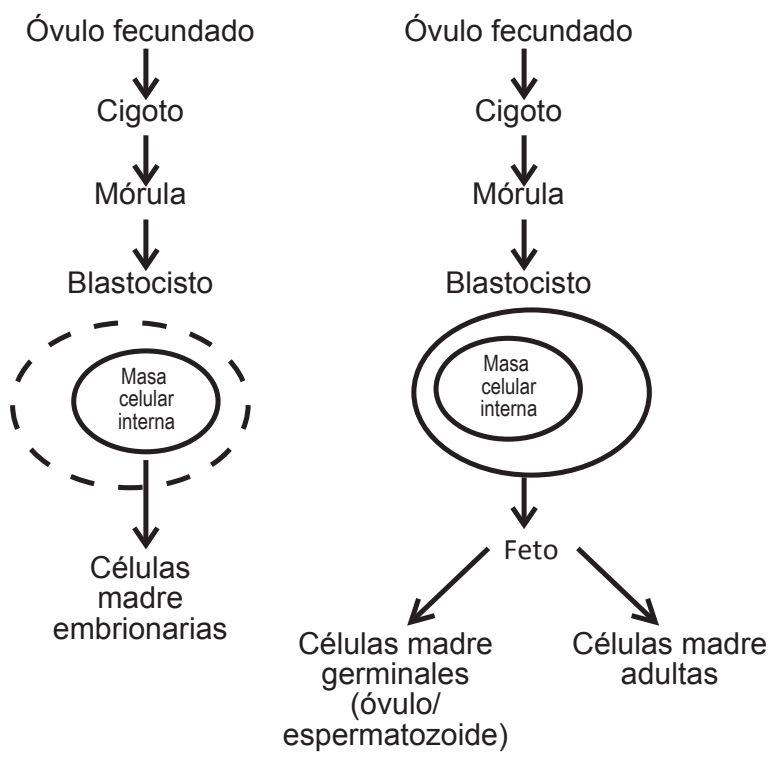

Figura 1. Tipos de células madre derivadas de las células pluripotentes del blastocisto

se trate solo de paliativos, sintomáticos simplemente, como lo son algunos tratamientos actuales, que obligan al paciente a recibir medicación de por vida. Las terapias con $\mathrm{CM}$ son tratamientos que emplean $\mathrm{CM}$, células derivadas de $\mathrm{CM}$ o factores recolectados de $\mathrm{CM}$ para reemplazar o reparar tejidos dañados mediante trasplantación directa o reclutamiento del propio paciente para su autorreparación. De allí la denominación de la "promesa terapéutica" para las CM. Se espera que puedan utilizarse exitosamente en el tratamiento de la diabetes, la enfermedad de Alzheimer, enfermedades cardiacas, Parkinson y muchas más.

Las CM nacen y se desarrollan con la vida misma, desde la concepción, cuando el espermatozoide fecunda al óvulo y se forma el huevo o zigoto, hasta su presencia y evolución en los tejidos del adulto. La Figura 1 presenta un esquema de las fuentes de células madre actualmente conocidas. Desde el punto de vista de su evolución, consideramos dos fases fundamentales para las CM presentes en el organismo.

\section{PRIMERA FASE: CÉLULAS MADRE EMBRIONARIAS (CME)}

Las células madre embrionarias (CME), tal como su nombre lo sugiere, son obtenidas a partir de embriones viables ${ }^{(1)}$, específicamente, la masa interna de células del blastocisto, el cual se forma en los humanos entre tres o cinco días después de que un ovocito es fertilizado por un espermatozoide. Efectivamente, en esta primera fase, el zigoto se divide en dos células, que por su apariencia similar se las conoce como células indiferenciadas, estas dos vuelven a dividirse y serán cuatro y luego en ocho que es una formación conocida como mórula. Siguen dividiéndose así sucesivamente hasta llegar a un número aproximado de setenta a cien células, que se conocen como el blastocisto. Las CM de la mórula son las de mayor potencia, denominadas totipotentes y son capaces de crear un ser completo; las segundas del blastocisto son pluripotentes, esto es que pueden transformarse en casi todos los tipos de células del organismo, excepto la placenta.

Por su potencia las CME se clasifican en:

a) Las células madre totipotentes tienen la capacidad para formar un organismo que incluye, además de las tres capas embrionarias (endodermo, mesodermo y ectodermo), las CM germinales - óvulo y espermatozoides - como también las extraembrionarias, especialmente la placenta, y son las primeras células que constituirán la mórula. Conforme avanza el desarrollo del embrión, las células que lo constituyen van disminuyendo su potencia, se hacen pluripotentes y luego multipotentes, que forman células de una sola capa embrionaria de las tres que conforman el organismo. Fue a partir del cultivo exitoso de las CME humanas que esta área de la medicina regenerativa fue establecida. ${ }^{(1)}$

b) Las células madre pluripotentes son aquellas que pueden diferenciarse en células de cualquiera de las tres capas embrionarias, pero no en células extraembrionarias. Por lo tanto, no pueden originar tejidos que hagan posible el desarrollo de un organismo completo. Sin embargo, si se las extrae del blastocisto se impedirá la continuación de la creación de una vida. Esta interrupción para favorecer un tratamiento que aun cuando pudiera ser satisfactorio y beneficioso, no es aceptado desde el punto de vista ético, porque el fin de la ciencia, por encima de todo, es proteger la vida humana. Por ejemplo, en los Estados Unidos de Norteamérica, durante la administración de G. W. Bush se prohibió la utilización de fondos públicos federales para investigaciones que incluyan en sus estudios CME ${ }^{(2,3)}$. Mientras que durante la administración de Obama se establecieron otros criterios para regular el empleo de CME a fin de encontrar un balance entre estudios de ciencia básica y aplicaciones éticamente aceptables.

\section{SEGUNDA FASE: CÉLULAS MADRE ADULTAS (CMA)}

La segunda fase es aquella que se refiere a las $\mathrm{CM}$ que constituyen el cuerpo humano después del nacimiento 
(del adulto, por extensión del término). Se encuentran en el organismo humano en esta fase adulta las células multipotentes y las unipotentes, estas últimas solo pueden crear un tipo de células.

a) Las células madre multipotentes son células que solo pueden diferenciarse en una capa embrionaria. En el Perú, la mayoría de pruebas clínicas y de carácter experimental utilizan este tipo de células que no se obtienen de embriones, sino de tejidos adultos, a las que se denomina células madre adultas (CMA), que tienen la propiedad de diferenciarse en células del órgano en el que se encuentran y así regenerar las células que el cuerpo va perdiendo a través de los años. Entre estas tenemos las CM hematopoyéticas que se encuentran a la base de una jerarquía de células que van diferenciándose en células progenitoras hematopoyéticas, las cuales, a su vez, se diferencian en células progenitoras hematopoyéticas mieloides que dan lugar a las plaquetas y glóbulos rojos; y células progenitoras hematopoyéticas linfoides que dan lugar a las células terminalmente diferenciadas del sistema inmune ${ }^{(4)}$. Por razones históricas, las CM hematopoyéticas son las más caracterizadas, pero sin una extensa manipulación genética en el laboratorio éstas no pueden dar origen a otras células del cuerpo humano de la misma manera en que por ejemplo, las CM neuronales no pueden dar lugar a CM hematopoyéticas. Las CM neuronales se diferencian en células progenitoras neuronales del tipo 1, tipo 2 y tipo 3 que dan lugar a neuronas maduras posmitóticas (5). Asimismo, también se han descrito con abundante detalle a las CM de piel y las CM intestinales ${ }^{(6)}$.

b) Las células madres unipotentes se diferencian en un único tipo celular y no ofrecen importante amplitud de diferenciación celular.

\section{CÉLULAS MADRE PLURIPOTENTES INDUCIDAS (IPS)}

Durante la última década del siglo $X X$ y primera del siglo XXI, los trabajos más importantes referidos a $\mathrm{CM}$ se desarrollaban con CME, lo cual permitió que se establecieran conceptos y técnicas in vitro e in vivo propias de la disciplina. Fuentes importantes de CME humanas han sido los embriones que quedan después de un proceso de fertilización in vitro asistida que se conservan congelados, sin posibilidad de utilización posterior. Todo ello a pesar del fuerte rechazo ético.

En algunos laboratorios de los Estados Unidos de América, los investigadores dedicados a estudios de CM comentaban con desánimo que, si bien ellos mantenían destacado avance respecto a estas investigaciones en su propio país, estaban muy atrasados con respecto a investigaciones en otros países, refiriéndose a las prohibiciones de su gobierno, que no existen en otros, para el otorgamiento de subvenciones a trabajos con CME.

En el Perú, tempranamente se publicaron artículos informativos al respecto y se hicieron esfuerzos en favor de su aplicación clínica pero solo de CMA ${ }^{(7)}$, generalmente con muestras de médula ósea obtenidas de la cresta ilíaca. Recientemente, se han publicado artículos en revistas indizadas ${ }^{(8,9)}$ de investigadores que iniciaron trabajos experimentales in vitro e in vivo en animales, aunque también con CMA, derivadas de tejido adiposo, por ejemplo. En todos estos casos se están afinando técnicas y mejorando metodologías que aún requieren perfeccionamiento, mejor equipamiento y mayor especialización, pero constituyen un loable esfuerzo en favor de un destacado desarrollo futuro en el área de $\mathrm{CM}$ en el Perú.

Gracias a los esfuerzos por aliviar las preocupaciones y limitaciones éticas, se recibió con mucho entusiasmo el artículo publicado en el 2006 en la revista Cell (10) por el equipo de Shinya Yamanaka, cirujano de la Universidad de Kioto. Se describió un procedimiento para obtener $\mathrm{CM}$ a partir de células adultas, es decir, un proceso inverso al que se inicia en la concepción y continúa en el desarrollo del embrión hasta llegar a la célula adulta. Así, se comenzaba con células adultas y se terminaban en células madre pluripotentes, ¡y ya sin el problema ético!

En esta experiencia se trabajó utilizando como células diana a fibroblastos de ratón a los que se les transfirió cuatro genes, asociados a las $\mathrm{CME}$, que codifican los factores de transcripción OCT3/4, SOX2; KLF4 y c-MYC, utilizando retrovirus como medios de transporte, e iniciando entonces una reprogramación celular que transforma a la célula adulta en célula madre pluripotente, a la que Yamanaka denominó célula madre pluripotente inducida, representada por sus siglas en inglés iPS.

Este éxito notable, que cambió significativamente el panorama que ofrecían las CM hasta entonces, presentaba un problema, que debía resolverse: impedir la formación de tumores que se generaban en porcentajes elevados. Se suprimió el gen c-MYC, oncogénico en un $20 \%$, que realmente no era necesario y se sugirió reemplazar el vehículo retrovirus por adenovirus. Thomson de EE.UU. ${ }^{(11)}$ utilizó los genes exógenos, OCT4, SOX2, NANOG y LIN28 y el vehículo, que algunos conocen como naves transportadoras, por lentivirus. Los adenovirus, además de no incorporar ninguno de sus genes al genoma de la célula adulta a reprogramar, no producen mutagénesis insercional, esto permite mejorar la calidad del proceso al evitar la formación de oncogenes o la afectación de genes 
necesarios. Muchas variantes se siguen combinando con el objetivo señalado. Lamentablemente, muchas de ellas afectan al proceso de reprogramación celular. Yamanaka en su primera experiencia solo logró un 0,1 a $1 \%$ de células iPS. El año siguiente, el 2007, Takahashi y colegas miembros del equipo liderado por Yamanaka obtuvo células iPS ${ }^{(12)}$ a partir de fibroblastos humanos.

Las iPS son similares a las CME, tanto morfológicamente como en diversas propiedades que las caracterizan. La Figura 2 sintetiza, por un lado, el proceso de diferenciación mediante el cual a partir de células pluripotentes se originan las diferentes capas embrionarias de las que finalmente se formarán los órganos y sistemas del adulto y, por otro lado, el proceso de reprogramación que permite a partir de células adultas obtener iPS que sean capaces de generar células adultas terminalmente diferenciadas. Además, la división celular se realiza con una frecuencia de mitosis alta para ambos casos y también se expresan los mismos marcadores que pueden detectarse con pruebas inmunohistoquímicas. En el Perú se trabaja con este tipo de marcadores y ya se poseen citómetros de flujo (Universidad de San Marcos, Universidad Científica del Sur), instrumentos que no solo cuentan células sino que, y muy importante, caracterizan fenotípicamente sus componentes marcadores - en este caso ambos tipos de CM. Sin embargo, es necesario que, además, se desarrollen metodologías para la caracterización funcional de cada linaje debido a que los marcadores empleados por citometría de flujo no son necesariamente específicos de $\mathrm{CM}$. Las combinaciones de anticuerpos que identifican patrones de expresión para los diferentes tipos de CM han sido establecidas en forma arbitraria por acuerdo de grupos de trabajo cooperativos, para poder comparar los diferentes estudios. Además, las iPS se diferencian en varios tipos de células de las tres capas germinales del embrión (ectodérmica, mesodérmica y endodérmica) tales como neuronas, fibroblastos, osteoblastos, miocitos, hepatocitos, entre otros. En el Perú se ha logrado caracterizar algunas de estas células como las neuronas, células mesenquimales, hepatocitos, de piel, pero a partir de células adultas.

Por todos estos resultados innovadores Shinya Yamanaka recibió el Premio Nobel de Fisiología o Medicina 2012, justo reconocimiento que compartió con el británico John B. Gurdon de las universidades de Oxford y Cambridge, quien en 1962 clonó un renacuajo por primera vez. La clonación es otra forma de reprogramación celular, pero igualmente rechazada por consideraciones éticas similares a aquellas que se adjudicaron a las pruebas anteriores con CME humanas.

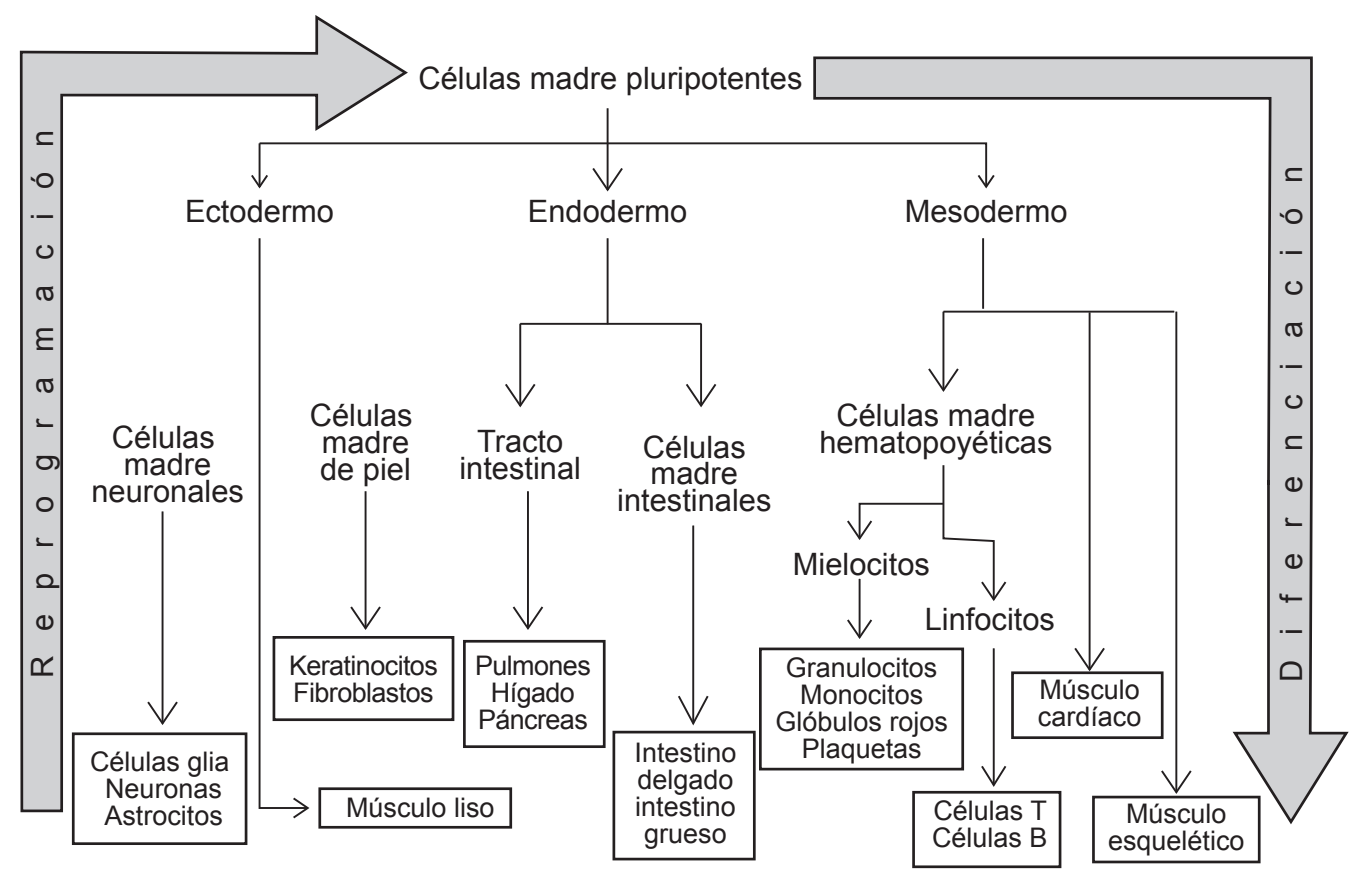

Figura 2. Algunos ejemplos de células terminalmente diferenciadas por capa embrionaria a partir de las células pluripotentes del blastocisto 


\section{CÉLULAS MADRE CARCINOGÉNICAS (CMC)}

Un aspecto diferente de los estudios de CM, emplea los conceptos de CM para el estudio de los mecanismos del cáncer y la propuesta de terapias antineoplásicas. El modelo de CMC permite explicar las recaídas en los tratamientos de cáncer con terapias citorreductoras ${ }^{(13-15)}$. Es decir, se supone que durante la iniciación y progresión del cáncer, algunas células cancerosas adquieren las características de CM tales como autorrenovación que hace posible que células cancerosas establezcan una jerarquía celular que tiene como base a CMC, de manera que el tejido es reemplazado por células en diferentes estados de diferenciación descendientes de células cancerosas o cuya diferenciación ha sido bloqueada ${ }^{(16,17)}$. Dado que la mayoría de las terapias antineoplásicas están orientadas a atacar a las células que se están replicando activamente, las CMC pueden sobrevivir, restablecer el tejido canceroso y dar lugar a las recaídas. Si bien este modelo se inició mediante estudios en leucemias, la participación de CMC en otros procesos como la generación de adenomas en el intestino, glioblastomas y carcinomas de células escamosas fueron demostradas en el año 2012 en revistas de alto impacto ${ }^{(18)} y$ en estudios realizados en la Universidad Científica del Sur de Lima, que demuestran la presencia del marcador de pluripotencia OCT4 y del factor de transcripción nuclear NF-kB en tumores cutáneos químicamente inducidos en ratones ${ }^{(19)}$ y en tumores mamarios caninos ${ }^{(20)}$. Al igual que para los otros tipos de CM descritos, existe mucho por trabajar en este campo y factores que participan en el posible desarrollo de las CMC que aún necesitan ser esclarecidos.

\section{ASPECTOS CLÍNICOS DE CÉLULAS MADRE}

Contrario a la percepción del público en general, el rango de enfermedades para las cuales hay aplicaciones validadas e incorporadas en guías terapéuticas basadas en $\mathrm{CM}$ es aún pequeño. En el Perú, la desesperación de pacientes y la oferta no regulada de tratamientos experimentales con $\mathrm{CM}$ ha llevado a que se convierta en uno de los países de destino del llamado "turismo con células madre" (21).

La Tabla 1 contrasta las diferencias en cuanto a las características de las distintas CM para su empleo con fines terapéuticos. En el Perú, la aplicación clínica de CME con fines terapéuticos está limitada, debido a consideraciones éticas y legales ${ }^{(2,3)}$. Algunas enfermedades y desórdenes hematológicos y del sistema inmune son tratados eficazmente con CMA del sistema hematopoyético. Las CM hematopoyéticas se emplean en los trasplantes de progenitores y $\mathrm{CM}$ hematopoyéticas (TPCMH) y son obtenidas mediante aspiración de la cresta ilíaca o a través de aféresis de sangre periférica luego de su movilización con el

Tabla 1. Características de las distintas células madre con aplicaciones en medicina regenerativa

\begin{tabular}{|c|c|c|c|}
\hline Características & $\begin{array}{c}\text { Células madre } \\
\text { embrionarias (CME) }\end{array}$ & Células madre adultas (CMA) & $\begin{array}{l}\text { Células pluripotentes inducidas } \\
\text { (iPS) }\end{array}$ \\
\hline $\begin{array}{l}\text { Potencial } \\
\text { regenerativo }\end{array}$ & Pluripotentes & Multipotentes & Pluripotentes \\
\hline Fuentes & Blastocisto & $\begin{array}{l}\text { Cordón umbilical } \\
\text { Tejido adiposo } \\
\text { Médula ósea } \\
\text { Sangre de pacientes tratados con agentes de } \\
\text { movilización }\end{array}$ & $\begin{array}{l}\text { Fibroblastos } \\
\text { Células hematopoyéticas } \\
\text { empobrecidas de células con linaje }\end{array}$ \\
\hline Aplicaciones & $\begin{array}{l}\text { Tamizaje para encontrar } \\
\text { nuevas estrategias } \\
\text { terapéuticas } \\
\text { Estudios del desarrollo } \\
\text { embrionario }\end{array}$ & $\begin{array}{l}\text { Tamizaje para encontrar nuevas estrategias } \\
\text { terapéuticas } \\
\text { Estudios de los linajes celulares de diferentes } \\
\text { órganos, tejidos y sistemas } \\
\text { Terapias de reemplazo celular en forma } \\
\text { alogénica o autóloga (de mayor interés) } \\
\text { Terapias para la regeneración con factores } \\
\text { de células madre }\end{array}$ & $\begin{array}{l}\text { Tamizaje para encontrar nuevas } \\
\text { estrategias terapéuticas } \\
\text { Estudios de enfermedades donde es } \\
\text { difícil conseguir tejido primario } \\
\text { Terapias de reemplazo celular } \\
\text { autólogo }\end{array}$ \\
\hline $\begin{array}{l}\text { Posibles modos } \\
\text { de acción en } \\
\text { aplicaciones } \\
\text { clínica }\end{array}$ & $\begin{array}{l}\text { Actividad angiogénica } \\
\text { Estimulantes de la } \\
\text { proliferación }\end{array}$ & $\begin{array}{l}\text { Reemplazo celular } \\
\text { Actividad angiogénica } \\
\text { Quimiotaxis } \\
\text { Inmunomodulación } \\
\text { Estimulantes de la proliferación }\end{array}$ & $\begin{array}{l}\text { Reemplazo celular } \\
\text { Actividad angiogénica } \\
\text { Quimiotaxis } \\
\text { Inmunomodulación } \\
\text { Estimulantes de la proliferación }\end{array}$ \\
\hline Limitaciones & $\begin{array}{l}\text { Éticas } \\
\text { Legales } \\
\text { Riesgo de teratomas } \\
\text { Rechazo inmunológico }\end{array}$ & $\begin{array}{l}\text { Cantidad } \\
\text { Calidad }\end{array}$ & $\begin{array}{l}\text { Cantidad } \\
\text { Calidad } \\
\text { Riesgo de teratomas } \\
\text { Riesgo de mutagénesis con ciertas } \\
\text { tecnologías disponibles }\end{array}$ \\
\hline
\end{tabular}


factor de crecimiento G-CSF, por sus siglas en inglés. Mucho antes del desarrollo de los conceptos de CM, los médicos han estado transfiriendo $\mathrm{CM}$ hematopoyéticas mediante TPCMH desde hace más de 50 años, y existen técnicas establecidas para la recolección de CM hematopoyéticas con fines clínicos ${ }^{(4)}$. El cordón umbilical se ha propuesto como una posible fuente para TPCMH y su potencial como fuente de CM hematopoyéticas y mesenquimales ha sido ampliamente acogido en el Perú dada la existencia de varios bancos privados y el interés por crear un banco de carácter público ${ }^{(22,23)}$. En estudios preclínicos, en nuestro país se viene trabajando en la caracterización de la acción regeneradora del secretoma obtenido de las CMA derivadas del cordón umbilical ${ }^{23,24)}$. Otros tratamientos con CM emplean CM hematopoyéticas para dolencias no hematopoyéticas o inmunes, como por ejemplo, con aplicaciones para dolencias cardiacas y oculares que, si bien siguen siendo experimentales, tienen resultados intermedios alentadores ${ }^{(25-28)}$. Es decir, todavía se está recogiendo información inequívoca de estudios clínicos apropiados que demuestren si son seguros y/o funcionales (29). Finalmente, los estudios clínicos en curso permitirán determinar los protocolos estandarizados para la recolección, preparación y administración de CMA.

Otras CMAde tejidos específicoso mesenquimales podrían cumplir también una función en el trasplante de tejidos. Cabe mencionar que pese a la amplia literatura existente sobre el potencial clínico de las CM mesenquimales, los nuevos conocimientos y el refinamiento de técnicas para la caracterización de estas CMA han llevado a reevaluar sus definiciones y conceptos, en general. Habitualmente, en la literatura se refieren a las $\mathrm{CM}$ mesenquimales como aquellas aisladas del estroma o tejido conectivo que se encuentra alrededor de órganos y tejidos, por lo que ahora se prefiere llamarlas CM estromales. Las primeras $\mathrm{CM}$ estromales en ser estudiadas fueron las provenientes de la región semisólida de la médula ósea y se demostró que son capaces de diferenciarse en osteoblastos, cartílagos y adipocitos. Luego, se han podido derivar de tejido adiposo y de la mesénquima del cordón umbilical. Sin embargo, existen controversias con implicaciones terapéuticas en cuanto a la composición precisa de estos compartimentos y los tipos de células terminalmente diferenciadas que se pueden obtener, dado que existen una serie de factores que lo determinan tales como de dónde se aíslan, cómo se aíslan y cómo se cultivan ${ }^{(30,31)}$. Las CM limbocorneales ${ }^{(32)}$ para el tratamiento de algunas afecciones de la córnea y la utilización de CM mesenquimales para el tratamiento de la enfermedad injerto-contra-huésped que puede presentarse como secuela del TPCMH han sido recientemente validadas clínicamente e incorporadas en guías terapéuticas de varios países ${ }^{(33)}$. En el Perú, se han reportados estudios clínicos experimentales que emplean la misma manipulación de las células hematopoyéticas autólogas establecida para TPCMH junto a estrategias quirúrgicas con rutas para la distribución en los órganos afectados como el cerebro ${ }^{(34)}$ y el corazón ${ }^{(35)}$. Si bien estos estudios sugieren que los protocolos experimentales no causan daño inmediato, no existen aún reportes de estudios diseñados para establecer la eficacia de estos tratamientos.

La aplicación terapéutica de iPS podría convertirse en la estrategia fundamental para las terapias celulares autólogas o personalizadas ${ }^{(12,36)}$, dado que existe un número creciente de publicaciones de ciencia básica que demuestran su potencial y su viabilidad con fines terapéuticos ${ }^{(37-45)}$. Por otro lado, las estrategias alogénicas harían posible desarrollar líneas celulares que puedan ser empleadas como medicamentos celulares. La Tabla 2 sintetiza los avances en cuanto a la condición de los pacientes donantes en los cuáles ha sido posible convertir células somáticas mediante diversos métodos en iPS. Asimismo, existen esfuerzos de ciencia básica a nivel internacional por promover la conversión directa de células de un linaje a otro mediante manipulación genética ${ }^{(46-50)}$ sin la necesidad de generar cultivos de iPS, pero ninguno ha llegado más allá de pruebas de laboratorio.

Si bien las CMA y las iPS ya se emplean como herramientas idóneas para estudios farmacológicos y toxicológicos ${ }^{(51)}$, los ejemplos de traslación al ámbito

Tabla 2. Condición de los pacientes donantes en los cuáles ha sido posible convertir células somáticas mediante diversos métodos de generación de células pluripotentes inducidas (iPS)

\begin{tabular}{llc}
\hline $\begin{array}{l}\text { Condición de los pacientes } \\
\text { donantes }\end{array}$ & $\begin{array}{l}\text { Fuente de } \\
\text { células }\end{array}$ & Referencias \\
\hline Anemia de células falciformes & Fibroblastos & 37 \\
\hline Anemia de Fanconi & Fibroblastos & 38 \\
\hline Talasemia & Fibroblastos & 39 \\
\hline Síndrome de X frágil & Fibroblastos & 40 \\
\hline Diabetes & Fibroblastos & 41 \\
\hline $\begin{array}{l}\text { Varias enfermedades } \\
\text { metabólicas }\end{array}$ & Fibroblastos & 41 \\
\hline Parkinson & Fibroblastos & 41 \\
\hline Trisomía 21 & $\begin{array}{l}\text { Fibroblastos } \\
\text { Tratamiento con agentes de } \\
\text { movilización hematopoyética }\end{array}$ & $\begin{array}{l}\text { hematopoyé- } \\
\text { ticas empo- } \\
\text { brecidas de } \\
\text { células con } \\
\text { linaje }\end{array}$ \\
\hline Leucemia mieloide aguda & $\begin{array}{l}\text { Fibroblastos } \\
\text { Células insu- }\end{array}$ & 43 \\
\hline Saludables & $\begin{array}{l}\text { lares beta del } \\
\text { páncreas }\end{array}$ & 44 \\
\hline
\end{tabular}


clínico a nivel mundial son escasos, principalmente debido a obstáculos relacionados con la cantidad y calidad de las células requeridas para la aplicación terapéutica. Por esta razón, es vital que se realicen mayores esfuerzos concertados en ciencias básicas e ingeniería que contribuyan e informen la práctica clínica. Así, por ejemplo, en los EE.UU. se continúan generando las reglas de juego para poder acelerar el desarrollo de nuevas terapias que aprovechen las $\mathrm{CM}^{(52)}$ y la Sociedad Internacional para la Investigación en Células Madre (ISSCR, en inglés) se encuentra en el proceso de consulta del borrador de una "Guía para los Estudios de Ciencia Básica y Traslación Clínica de Células Madre”.

En el caso de la cantidad de células, los esfuerzos por encontrar medios de cultivo químicamente definidos han permitido formulaciones que no emplean proteínas de origen animal, sino proteínas humanas recombinantes como el factor de CM (SCF, en inglés) y cascadas bioquímicas específicas ${ }^{(51,53,54)}$. Sin embargo, la aplicación clínica de estas formulaciones continúa siendo limitada debido a que dadas sus características inherentes, las CM 1. no pueden ser producidas y analizadas en grandes cantidades, 2 . existen altos costos asociados a la producción de proteínas recombinantes y 3. se entiende poco sobre los complejos procesos farmacocinéticos involucrados. En el laboratorio de cultivos celulares de la Universidad Científica del Sur de Lima se emplea el tamizaje de extractos vegetales a fin de proponer formulaciones alternativas que permitan reemplazar o disminuir las concentraciones de los factores del crecimiento de alto costo ${ }^{(9)}$.

Los estudios orientados a la calidad requieren, a nivel de laboratorio, una caracterización detallada de los estados de diferenciación, estabilidad genética y cambios metabólicos. Estos estudios, a su vez, servirán como base para el trabajo interdisciplinario con especialistas de ingeniería para proponer metodologías de manufactura en biorreactores bajo estrictos controles de calidad que, finalmente, hagan posible estudios clínicos apropiados. Para la mayoría de las enfermedades, aún se está determinando qué células son las idóneas para funcionar en su capacidad de reparar un daño tisular particular y cuál es la fuente más adecuada para conseguir estas células. Por ejemplo, en el caso de los cultivos de iPS se requiere la coexistencia de diferentes tipos de células que respondan de diferente manera a los protocolos de diferenciación, pero que al momento de ser transferidas a un paciente puedan ser disociadas, lo cual puede conllevar a efectos inesperados en sus características regenerativas.
Finalmente, se sabe poco sobre los efectos secundarios y la seguridad a largo plazo que deben ser determinados. Una de las mayores preocupaciones en este ámbito es la formación de granulomas, debido a que las células trasplantadas pueden permanecer durante años en el cuerpo del receptor del trasplante. Por lo tanto, es extremadamente importante un cuidadoso monitoreo y un seguimiento clínico de los pacientes que han recibido terapias con $\mathrm{CM}$.

A fines del año 2014, la prestigiosa revista Science hizo una encuesta entre los científicos; después de varios tamices reunió a los cinco estudios más votados, los cuales puso a consideración de sus lectores, entre ellos el referido al tratamiento de diabetes con CM. En el conteo final se ubicó a este último en cuarto puesto. Se comenta que se ha avanzado bastante en este tema, pero particularmente en la obtención de células beta de los islotes de Langerhans del páncreas a partir de CME. Dadas las similitudes antes mencionadas, es muy posible que también puedan lograrse con iPS. En Lima, en el Seminario Internacional "Avances en la Biología de las Células Madre y Terapia Celular" (55), el Dr. Bernat Soria, experto español en CM y diabetes, fue muy cauto al respecto, pero cabe aclarar que en aquel entonces todavía no se habían obtenido otros logros que se publicaron en septiembre de 2014 por el laboratorio de Kieffer junto al Equipo BetaLogics ${ }^{(56)}$. Luego, en octubre de 2014, el laboratorio de Douglas Melton demostró que a partir de células pluripotentes se pueden originar células capaces de producir insulina y que responden a los niveles sistémicos de glucosa in vivo ${ }^{(57)}$. Si bien este logro es significativo, después de más de 10 años de trabajo, queda pendiente resolver la ruta de administración, o la manera en que estas células serían trasplantadas en humanos, dado que necesitan cubrir una superficie mayor que en animales de experimentación, para ser efectivas, además de burlar el sistema inmune. Aún no hay información fehaciente de ensayos clínicos efectuados al respecto.

Contribución de autoría: JAP y FC han participado en la concepción y diseño del artículo, la redacción, revisión crítica y aprobación de la versión final del artículo. Asimismo, JAP y FC obtuvieron financiamiento.

Fuentes de financiamiento: el presente trabajo fue financiado mediante el Programa de Estancias Cortas para Investigadores No Residentes en el Perú de Innóvate Perú N. ${ }^{\circ}$ 301-PNICPECIP-2015 otorgado a FC bajo el patrocinio de la Universidad Científica del Sur.

Conflictos de interés: los autores declaran no tener conflictos de interés en la publicación de este artículo. 


\section{REFERENCIAS BIBLIOGRÁFICAS}

1. Thomson JA, Itskovitz-Eldor J, Shapiro SS, Waknitz MA, Swiergiel JJ, Marshall VS, et al. Embryonic stem cell lines derived from human blastocysts. Science. 1998 Nov 6;282(5391):1145-7.

2. Gonzales Espinoza CR. Células madre, aspectos éticos y jurídicos

II. Docencia et Investigatio. 2013;15(2):75-85.

3. Arias-Stella J. Obama y la investigación en células madre embrionarias humanas. Acta Med Per. 2009;26(2):134-5.

4. Eaves CJ. Hematopoietic stem cells: concepts, definitions, and the new reality. Blood. 2015 Apr;125(17):2605-13. doi: 10.1182/ blood-2014-12-570200.

5. Kempermann G, Song H, Gage FH. Neurogenesis in the Adult Hippocampus. Cold Spring Harb Perspect Biol. 2015 Sep 1;7(9):a018812. doi: 10.1101/ cshperspect.a018812.

6. Goodell MA, Nguyen H, Shroyer N. Somatic stem cell heterogeneity: diversity in the blood, skin and intestinal stem cell compartments. Nat Rev Mol Cell Biol. 2015 May;16(5):299-309. doi: 10.1038/ nrm3980.

7. Brazzini-Arméstar A. Células Madre Adultas Autólogas - Aplicaciones y experiencias clínicas. Lima: Amolca; 2015.

8. Enciso Gutiérrez J, Amiel Pérez J, Guija Poma E, Fukusaki Yoshizawa A, Reátegui Arévalo O, Amiel Peña $\mathrm{D}$, et al. Actividad antioxidante del extracto hidroalcohólico de cuatro plantas medicinales y estimulación de la proliferación de fibroblastos. Rev Soc Quím Perú. 2010;76(1):73-9.

9. Enciso-Benavides N, Amiel-Pérez J, Guija-Poma E, Fukusaki-Yoshizawa A, Reátegui-Arévalo O, EncisoGutiérrez J. Obtención de extractos de plantas que estimulan la proliferación de una línea humana de células madre mesenquimales. Científica. 2011;8(2):89-97.

10. Takahashi K, Yamanaka S. Induction of pluripotent stem cells from mouse embryonic and adult fibroblast cultures by defined factors. Cell. 2006 Aug 25;126(4):663-76.
11. Yu J, Hu K, Smuga-Otto K, Tian S, Stewart R, Slukvin, II, et al. Human induced pluripotent stem cells free of vector and transgene sequences. Science. 2009 May 8;324(5928):797801. doi: 10.1126/science.1172482.

12. Takahashi K, Tanabe K, Ohnuki M, Narita M, Ichisaka T, Tomoda K, et al. Induction of pluripotent stem cells from adult human fibroblasts by defined factors. Cell. 2007 Nov 30;131(5):861-72.

13. Stangeland B, Mughal AA, Grieg Z, Sandberg CJ, Joel M, Nygård $S$, et al. Combined expressional analysis, bioinformatics and targeted proteomics identify new potential therapeutic targets in glioblastoma stem cells. Oncotarget. 20152015 Sep 22;6(28):26192-215. doi: 10.18632/ oncotarget. 4613 .

14. Kreso A, Dick JE. Evolution of the cancer stem cell model. Cell Stem Cell. 2014 Mar;14(3):275-91. doi: 10.1016/j.stem.2014.02.006.

15. Medema JP, Vermeulen L. Microenvironmental regulation of stem cells in intestinal homeostasis and cancer. Nature. 2011 Jun 15;474(7351):318-26. doi: 10.1038/ nature 10212 .

16. Brooks MD, Burness ML, Wicha MS. Therapeutic Implications of Cellular Heterogeneity and Plasticity in Breast Cancer. Cell Stem Cell. 2015 Sep 3;17(3):260-71. doi: 10.1016/j. stem.2015.08.014.

17. Rycaj K, Tang DG. Cell-of-Origin of Cancer versus Cancer Stem Cells: Assays and Interpretations. Cancer Res. 2015 Oct 1;75(19):4003-11. doi: 10.1158/0008-5472.CAN-15-0798.

18. McCarthy N. Cancer stem cells: Tracing clones. Nat Rev Cancer. 2012 Sep;12(9):579. doi: 10.1038/ nrc3354.

19. Enciso-Gutiérrez J, Amiel-Pérez J, Fabián-Domínguez F, Chu-Olivares J, Kuniyoshi S. Identificación inmunohistoquímica de células inmunoreactivas al marcador de indiferenciación Oct4 en neoplasia inducida por 7, 12-dimetilbenz(a) antraceno (DMBA) en ratones. Científica. 2012;9(2):111-6.

20. Enciso-Benavides N, Amiel-Pérez J, Enciso-Gutiérrez J. Expresión y distribución de los factores de transcripción cellular Oct4 y NF$\mathrm{kB}$ en tumors mamarios caninos. Científica. 2012;9(1):10-6.

21. Connolly R, O'Brien T, Flaherty G. Stem cell tourism--a web-based analysis of clinical services available to international travellers. Travel Med Infect Dis. 2014 Nov-Dec;12(6 Pt B):695-701.

22. Perú, Ministerio de Salud. El Perú contará con el primer banco público de células madre de cordón umbilical 2015 [Internet]. Lima: MINSA; 2015. Disponible en: http://www.minsa.gob. $\mathrm{pe} /$ ?op $=51 \&$ nota $=16033$ \#cabe_tag

23. Tejada Zevallos EH. Aspectos bioéticos en el uso de bancos de células madre de cordón umbilical. Tesis para obtener el grado de Magíster. Escuela de Postgrado de la Universidad Católica Santo Toribio de Mogrovejo. Chiclayo, Perú. 2013.

24. Cabrera C, Carriquiry G, Pierinelli C, Reinoso N, Arias-Stella J, Paino J. The role of biologically active peptides in tissue repair using umbilical cord mesenchymal stem cells. Ann N Y Acad Sci. 2012 Oct;1270:93-7. doi: 10.1111/j.1749-6632.2012.06727.x.

25. Hamshere S, Arnous S, Choudhury T, Choudry F, Mozid A, Yeo C, et al. Randomized trial of combination cytokine and adult autologous bone marrow progenitor cell administration in patients with non-ischaemic dilated cardiomyopathy: the REGENERATEDCM clinical trial. Eur Heart J. 2015 Nov 21;36(44):3061-9. doi: 10.1093/ eurheartj/ehv390.

26. Weiss JN, Levy S, Malkin A. Stem Cell Ophthalmology Treatment Study (SCOTS) for retinal and optic nerve diseases: a preliminary report. Neural Regen Res. 2015 Jun;10(6):982-8. doi: 10.4103/1673-5374.158365.

27. Granton J, Langleben D1, Kutryk MB, Camack N, Galipeau J, Courtman DW, et al. Endothelial NO-Synthase GeneEnhanced Progenitor Cell Therapy for Pulmonary Arterial Hypertension the PHACeT Trial. Circ Res. 2015 Sep 11;117(7):645-54. doi: 10.1161/ CIRCRESAHA.114.305951.

28. Patel AN, Mittal S, Turan G, Winters AA, Henry TD, Ince $\mathrm{H}$, et al. REVIVE Trial: Retrograde Delivery of 
Autologous Bone Marrow in Patients With Heart Failure. Stem Cells Transl Med. 2015 Sep;4(9):1021-7. doi: 10.5966/sctm.2015-0070.

29. Custodio N, Terapia con "células madre" en enfermedad de Parkinson: ¿dónde estamos?. Rev Neuropsiquiatr. 2014;77(1):1-2.

30. Viswanathan S, Keating A, Deans R, Hematti P, Prockop D, Stroncek DF, et al. Soliciting strategies for developing cell-based reference materials to advance mesenchymal stromal cell research and clinical translation. Stem Cells Dev. 2014 Jun 1;23(11):115767. doi: $10.1089 / \mathrm{scd} .2013 .0591$.

31. Lalu MM, McIntyre L, Pugliese C, Fergusson D, Winston BW, Marshall JC, et al. Safety of cell therapy with mesenchymal stromal cells (SafeCell): a systematic review and metaanalysis of clinical trials. PLoS One. 2012;7(10):e47559. doi: 10.1371/ journal.pone.0047559.

32. Holan V, Trosan P, Cejka C, Javorkova E, Zajicova A, Hermankova B, et al. A Comparative Study of the Therapeutic Potential of Mesenchymal Stem Cells and Limbal Epithelial Stem Cells for Ocular Surface Reconstruction. Stem Cells Transl Med. 2015 Sep;4(9):1052-63. doi: 10.5966/ sctm.2015-0039.

33. Sato K, Ozaki K, Mori M, Muroi K, Ozawa K. Mesenchymal stromal cells for graft-versus-host disease : basic aspects and clinical outcomes. J Clin Exp Hematop. 2010;50(2):79-89.

34. Brazzini A, Cantella R, De la Cruz A, Yupanqui J, León C, Jorquiera T, et al. Intraarterial autologous implantation of adult stem cells for patients with Parkinson disease. J Vasc Interv Radiol. 2010 Apr;21(4):443-51. doi: 10.1016/j.jvir.2010.01.008.

35. Rivas-Plata A, Castillo J, Pariona M, Chunga A. Bypass grafts and cell transplant in heart failure with low ejection fraction. Asian Cardiovasc Thorac Ann. 2010 Oct;18(5):425-9. doi: $10.1177 / 0218492310379939$.

36. Yu J, Vodyanik MA, Smuga-Otto $\mathrm{K}$, Antosiewicz-Bourget J, Frane JL, Tian S, et al. Induced pluripotent stem cell lines derived from human somatic cells. Science. 2007 Dec 21;318(5858):1917-20.

37. Hanna J, Wernig M, Markoulaki S, Sun CW, Meissner A, Cassady JP, et al.
Treatment of sickle cell anemia mouse model with iPS cells generated from autologous skin. Science. 2007 Dec 21;318(5858):1920-3.

38. Raya A1, Rodríguez-Pizà I, Guenechea G, Vassena R, Navarro S, Barrero MJ, et al. Disease-corrected haematopoietic progenitors from Fanconi anaemia induced pluripotent stem cells. Nature. 2009 Jul 2;460(7251):53-9. doi: $10.1038 /$ nature 08129 .

39. Chang CJ, Bouhassira EE. Zincfinger nuclease-mediated correction of $\alpha$-thalassemia in iPS cells. Blood. 2012 Nov 8;120(19):3906-14. doi: 10.1182/blood-2012-03-420703.

40. Kumari D, Swaroop M, Southall N, Huang W, Zheng W, Usdin K. High-Throughput Screening to Identify Compounds That Increase Fragile X Mental Retardation Protein Expression in Neural Stem Cells Differentiated From Fragile X Syndrome Patient-Derived Induced Pluripotent Stem Cells. Stem Cells Transl Med. 2015 Jul;4(7):800-8. doi: 10.5966/sctm.2014-0278.

41. Park IH, Arora N, Huo H, Maherali $\mathrm{N}$, Ahfeldt T, Shimamura A, et al. Disease-specific induced pluripotent stem cells. Cell. 2008 Sep 5;134(5):877-86. doi: 10.1016/j. cell.2008.07.041.

42. Lee JH, Mitchell RR, McNicol JD, Shapovalova Z, Laronde S, Tanasijevic B, et al. Single Transcription Factor Conversion of Human Blood Fate to NPCs with CNS and PNS Developmental Capacity. Cell Rep. 2015 Jun 9;11(9):1367-76. doi: 10.1016/j.celrep.2015.04.056.

43. Salci KR, Lee JH, Laronde S, Dingwall S, Kushwah R, Fiebig-Comyn $\mathrm{A}$, et al. Cellular reprogramming allows generation of autologous hematopoietic progenitors from AML patients that are devoid of patientspecific genomic aberrations. Stem Cells. 2015 Jun;33(6):1839-49. doi: 10.1002/stem.1994.

44. Doers ME, Musser MT, Nichol R, Berndt ER, Baker M, Gomez TM, et al. iPSC-derived forebrain neurons from FXS individuals show defects in initial neurite outgrowth. Stem Cells Dev. 2014 Aug 1;23(15):1777-87. doi: $10.1089 / \mathrm{scd} .2014 .0030$.

45. Bar-Nur O, Russ HA, Efrat $S$, Benvenisty N. Epigenetic memory and preferential lineage-specific differentiation in induced pluripotent stem cells derived from human pancreatic islet beta cells. Cell Stem Cell. 2011 Jul 8;9(1):17-23. doi: 10.1016/j.stem.2011.06.007.

46. Pang ZP, Yang N, Vierbuchen T, Ostermeier A, Fuentes DR, Yang TQ, et al. Induction of human neuronal cells by defined transcription factors. Nature. 2011 May 26;476(7359):2203. doi: $10.1038 /$ nature 10202 .

47. Du Y, Wang J, Jia J, Song N, Xiang $\mathrm{C}, \mathrm{Xu} \mathrm{J}$, et al. Human hepatocytes with drug metabolic function induced from fibroblasts by lineage reprogramming. Cell Stem Cell. 2014 Mar 6;14(3):394-403. doi: 10.1016/j. stem.2014.01.008.

48. Yang R, Zheng Y, Li L, Liu S, Burrows M, Wei Z, et al. Direct conversion of mouse and human fibroblasts to functional melanocytes by defined factors. Nat Commun. 2014 Dec 16;5:5807. doi: 10.1038/ ncomms6807.

49. Wada R, Muraoka N, Inagawa $\mathrm{K}$, Yamakawa $\mathrm{H}$, Miyamoto $\mathrm{K}$, Sadahiro $\mathrm{T}$, et al. Induction of human cardiomyocyte-like cells from fibroblasts by defined factors. PNAS. 2013 Jul 30;110(31):12667-72.

50. Zhang K, Liu GH, Yi F, Montserrat $\mathrm{N}$, Hishida T, Rodriguez Esteban $\mathrm{CR}$, et al. Direct conversion of human fibroblasts into retinal pigment epithelium-like cells by defined factors. Protein Cell. 2013 Jun 20.

51. Boitano AE, Wang J, Romeo R, Bouchez LC, Parker AE, Sutton SE, et al. Aryl hydrocarbon receptor antagonists promote the expansion of human hematopoietic stem cells. Science. 2010 Sep 10;329(5997):1345-8. doi: 10.1126/ science.1191536.

52. Knoepfler PS. From bench to FDA to bedside: US regulatory trends for new stem cell therapies. Adv Drug Deliv Rev. 2015 Mar;82-83:192-6. doi: 10.1016/j.addr.2014.12.001.

53. Lian X, Zhang J, Azarin SM, Zhu K, Hazeltine LB, Bao X, et al. Directed cardiomyocyte differentiation from human pluripotent stem cells by modulating Wnt $/ \beta$-catenin signaling under fully defined conditions. Nat Protoc. 2013 Jan;8(1):162-75. doi: $10.1038 /$ nprot.2012.150. 
54. Fares I, Chagraoui J, Gareau Y, Gingras S, Ruel R, Mayotte N, et al. Cord blood expansion. Pyrimidoindole derivatives are agonists of human hematopoietic stem cell self-renewal. Science. 2014 Sep 19;345(6203):1509-12. doi: 10.1126/science. 1256337.

55. Amiel-Pérez J. Uso de extractos de plantas como estimulantes de la expansión de células madre in vitro. En: Seminario Internacional: avances en la biología de las células madre y terapia celular; 5-6 de agosto de 2013; Lima, Perú. Lima: Universidad Científica del sur; 2013.

56. Rezania A, Bruin JE, Arora P, Rubin A, Batushansky I, Asadi A, et al. Reversal of diabetes with insulinproducing cells derived in vitro from human pluripotent stem cells. Nat Biotechnol. 2014 Nov;32(11):112133. doi: 10.1038/nbt.3033.

57. Pagliuca FW, Millman JR, Gürtler M, Segel M, Van Dervort A, Ryu JH, et al. Generation of functional human pancreatic $\beta$ cells in vitro. Cell 2014 Oct 9;159(2):428-39. doi: 10.1016/j. cell.2014.09.040.

Correspondencia: José Amiel-Pérez Dirección: Monte Umbroso 235 Dpto. 101 Santiago de Surco

Teléfono: (+511)945286932

Correoelectrónico:jamielp@cientifica.edu.pe

\section{http://twitter.com/rpmesp}

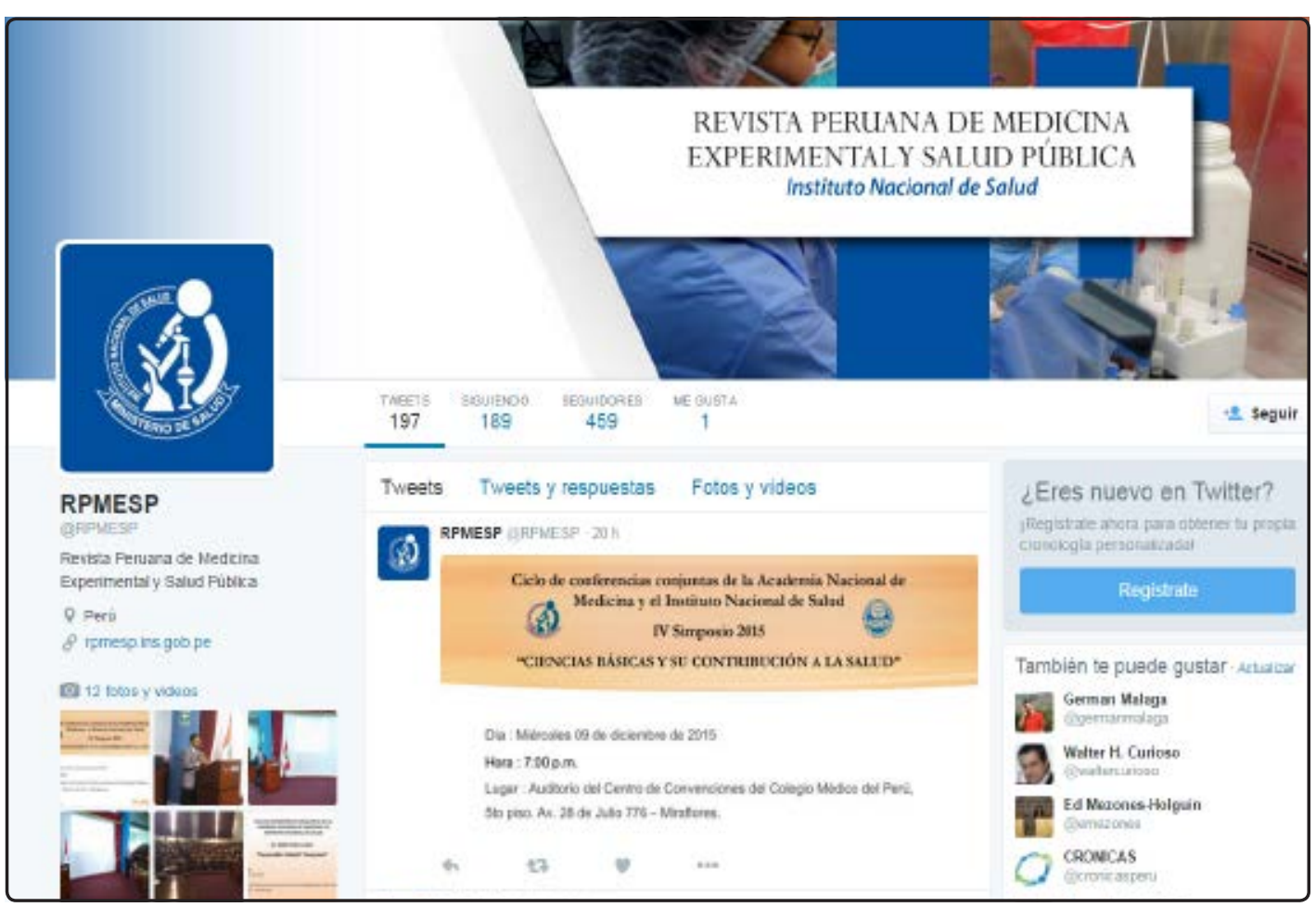

